\title{
THE SEAPLANE BASE IVO MONTI AT S. NICOLA VARANO (FG): A MONUMENT OF MILITARY ARCHEOLOGY, BETWEEN HISTORY AND PROTECTION
}

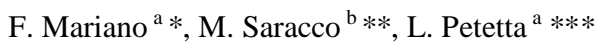 \\ a Dept. Dicea, Marche Polytechnic University, Via Brecce Bianche 12, Ancona, Italy - f.mariano@univpm.it, \\ leonardo.petetta@gmail.com \\ ${ }^{\mathrm{b}}$ Dept. Sfbct, University of Macerata, P.le Luigi Bertelli 1, Macerata, Italy - mauro.saracco@unimc.it
}

KEY WORDS: restoration, conservation, reuse, ruins, military archeology

\begin{abstract}
:
Built in the years between 1915 and 1918, and located on the west bank of the "Varano" Lake, a bay running along the village of "Cagnano Varano", the "Ivo Monti" seaplane base was erected on a pre-existing medieval settlement which belonged to the Benedictine Monks from the town of "San Nicola Imbuti".

During WWI, this seaplane base was turned, from a simple water airport, into a strategic military base for floatplanes. As a matter of fact, the large lagoon could be used as landing spot for the planes sent off to patrol the dalmatic coast, one of the historical regions of Croatia, then controlled by the Austrians.

After WWI, after the seaplane became an outdated technology, the "Ivo Monti" base was progressively dismantled and then totally abandoned at the beginning of the 1950s.

In 2014, considering the historical relevance of this site and the unmistakable architectural value of its elements, a research framework agreement was signed between the "DICEA" Department of Marche Polytechnic University and the city council of the town hosting the site, aimed at the development of shared scientific research projects revolving around the study, the valorisation, and the restoration of the military complex in question, which had been in a complete state of decay and neglect for too long.

The still ongoing research project mentioned presents two main missions: the first is the historical reconstruction, the geometric mapping, and the robustness analysis of the ruins, by studying and faithfully representing the state of deterioration of the building materials and of the facilities; the second is the identification and the testing of potential architectural solutions for the conversion and the reuse of the site and of its facilities.
\end{abstract}

\section{THE SEAPLANE BASE IVO MONTI OF SAN NICOLA VARANO A MONUMENT OF MILITARY ARCHEOLOGY, BETWEEN HISTORY AND PROTECTION}

\subsection{Introduction: the history*}

The importance of developing a national aviation industry and the creation of an aeronautical independent structure within the Italian Armed Forces had already been addressed since 1911, by the Italian Government, during the operation in the ItaloTurkish war and in particular in Libya with military use of aircraft. Just in 1914 the Minister of War Gen. Domenico Grandi, will present on June 11, the draft law for the establishment of the Air Force Corps.

This urgent strategic decision became urgent for the Italian parliament at the threshold of World War I. The "Air Force Corps", under the Ministry of War, was finally constituted with Royal Decree n. 11 of January 7, 1915.

Another Italian priorities was the establishment of the seaplanes section, commissioned in June 1913 by the Ministry of War, and placed at the service of the Navy as "Aeronautical Service of the Royal Navy". The next July 20 Admiral Paolo Thaon di Revel was appointed Chief of Staff of the Royal Navy; staunch supporter of Naval Aviation, gave a significant boost to the development and strengthening of the sector. On the night of May 24, 1915 Austrian seaplanes bombarded Venice. This and other raids on Italian territory aroused new focus on the development of aviation forces.

In this rapid and dramatic historical context, the seaplane base of San Nicola Varano, below the Gargano, immediately appeared as a strategic opportunity.

In fact, his position was favorable: central with respect to Ancona and Brindisi, hidden and protected to the west and south of the Mount of Elio and the Mount Lo Sfrizzo, separated from the sea by the strip of dunes of Varano Island, just off the Tremiti islands and the island of Pelagosa.

In addition, the area was located in front of the Austrian enemy zone: the islands curzolane, where the military commands and fleets of Austro-Hungarian army, were stationed.

It should be noted that the Italian decision to develop the fleet of seaplanes will prove successful both in World War I and in World War II. In those years Italy was preparing to become the nation's leading manufacturer of seaplanes, with world record then won by Italo Balbo in the '30s.

All this decreed the creation of a base for naval aviation, based in San Nicola Varano.

The historic site is still today a rare surviving relic of an early, broad and complex construction of military architecture of the First World War, of which today we celebrate the secular anniversary.

The seaplane works began after the summer of 1915, after the inspection of the site conducted in June by the Chief of Staff of the Italian Navy, Vice Admiral Paul Thaon Revel. 


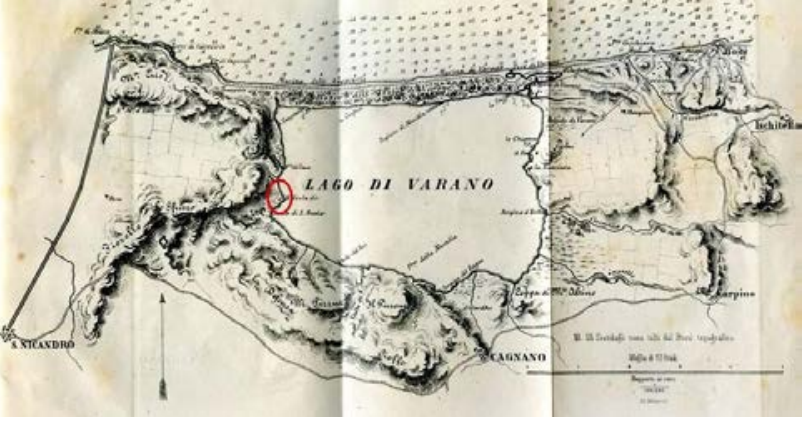

Figure 1. Cartography of the area (late 1800 c.a)

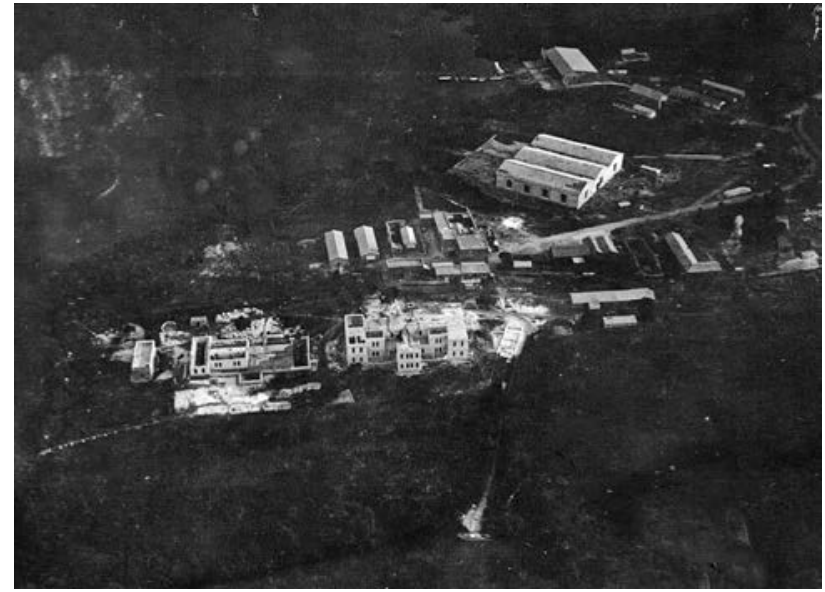

Figure 2. View of the complex under construction (1918 c.a)

At that time the only one building on the area was the ancient Benedictine monastery of St. Nichola Imbuti, the "cellam Santo Nicolay dello Imbuto”, dependent on Kalena abbeys (Peschici) and Santa Maria di Tremiti, owned here by the Canons Regular of the Lateran, from the eleventh century until 1782.

The attempts to develop this area, economically depressed and environmentally unhealthy, that culminated in 1906 with the request to the Government to transform the Lake Varano in a military cargo port, had failed. Now, the national political will, driven by military strategy, at the beginning of World War I, seemed concretely addressing the exploitation of the site, which was acquired in Maritime State Property.

The complex work of transformation, rehabilitation and construction of the complex was entrusted to the lieutenant, Count Alberto Ghe, and requested funding, design capabilities, managerial and interpersonal skills.

The living area of the seaplane station of San Nicola Varano was not realized all at once but in several stages to meet the following needs related to the increase in personnel and the expansion of its functions. The seaplane work began in the fall of 1915 and continued for some years, enriching structures, infrastructures and environments. Initially it was planned to accommodate the officers in the ex Benedictine monastery.

In 1916, however, with the arrival of new officers, it was built a new building, equipped by a dining room and conference room, on the first floor. Later, the arrival of thirty sailors demanded to build barracks able to accommodate 56 people. It was decided to build them next to the hangar that housed already 9 seaplanes. The first flight dates back to 31 May 1916. In June of that year they were made the first reconnaissance flights over curzolane islands of Lagosta and Pelagosa. The September 30,
1917 was finished a new hangar, ready to accommodate 15 hydroplanes Macchi L3.

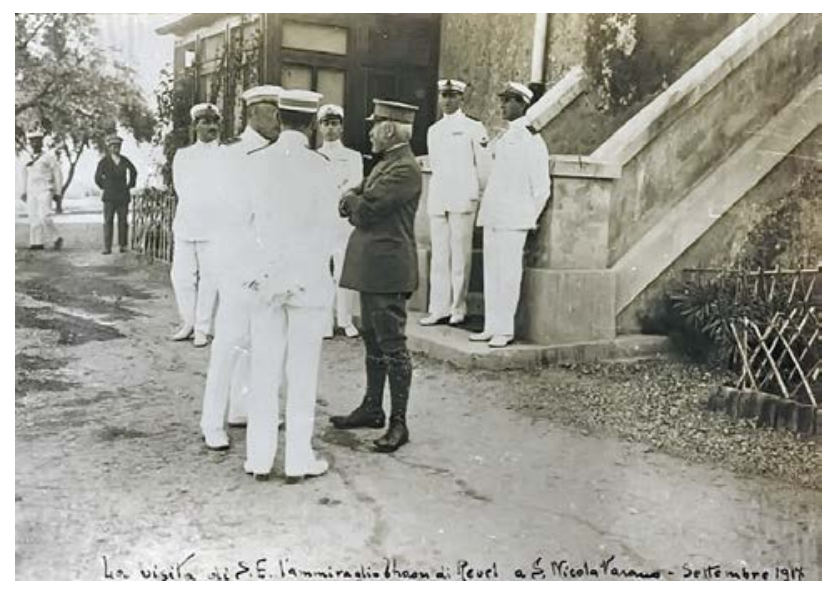

Figure 3. Officers and Admiral Thaon de Revel, visiting 13 sett.1917

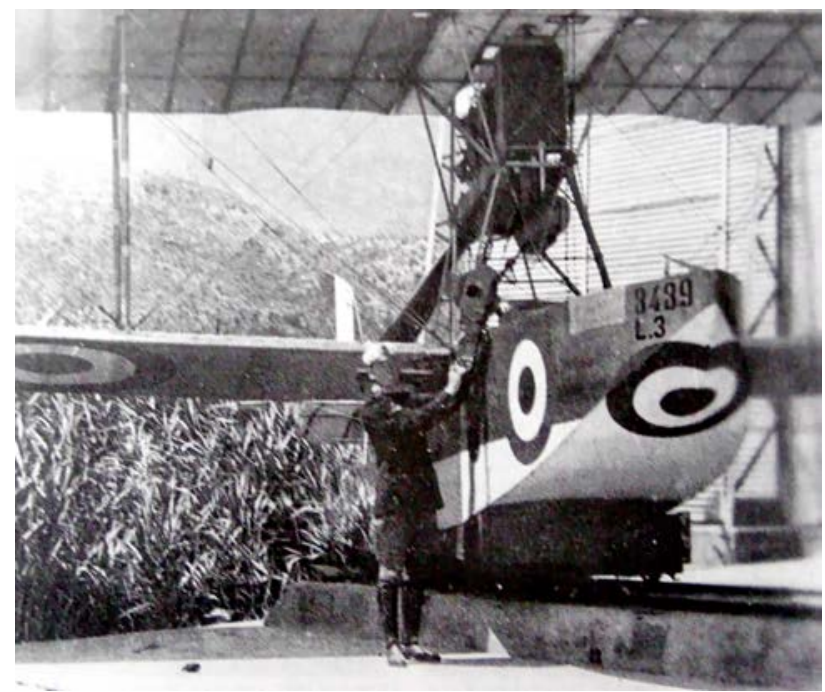

Figure 4. Seaplane Macchi L3, 1917

They were built: the shacks for the workers, the refectory, the kitchens with ovens, hangars, barracks and even the hospital with the military infirmary. Gradually, therefore, the seaplane was completed with elegant two floors buildings, sometimes with a basement, with straw yellow colored exterior walls, floors with colorful tiles and blue internal bases, english windows, colonnades of the balconies protected by sunscreen windproof, and the helices and stylized wings of the plane - Air Force symbol - placed on the gables and windows of buildings. With the passing of time, also the services were improved: in November 1915 he worked the telegraph, in 1916 the telegraph radio. From the second half of 1915 to 1918 greatly increased the presence of military and civilian personnel, pledged to make livable space around: workmen and skilled technicians: lieutenants, machinists, pilots, radio operators, sailors, workmen, builders, stokers, carpenters, tailors, barbers, cooks, officers, motorists. 


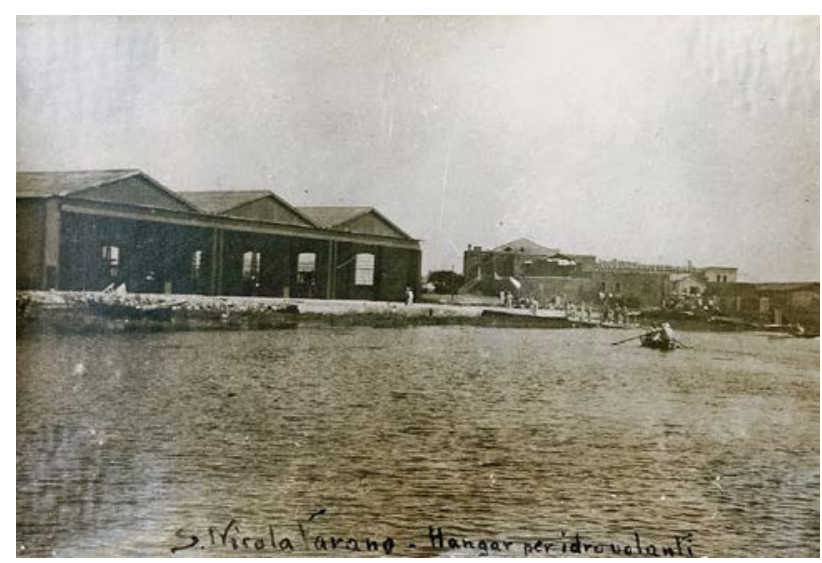

Figure 5. Hangars

It took more than three years to see the complete village, divided by an urban road system and rational and self-sufficient spaces, complemented by architectural finishes.

These, with careful observation, still show the changes of the constructive systems realized during works: from the initial square block systems in local stone Apricena, to the reinforced concrete pillar systems buffered with hollow bricks and air interspaces, from the horizontal elements in iron beams and vaults with prefabricated shaped bricks to the mixed floors of cement and bricks, with " original " reinforcements in iron straps linked by strips, etc. They appear gradually, then, prefabricated systems marked by industrial companies in northern Italy.

All details that denounce, obviously, extreme haste imposed on construction sites by the conflict, already begun.

In 1916, 150 men were stationed at the end of November 1917, there were 260 people at the end of December 300, in 1918 there were 400 workers, mostly builders sailors.

In 1918, when the seaplane was nearly completed, fortunately one breathed air of peace. It was hosted a visit of King Vittorio Emanuele III in 1918 and another by the Crown Prince Umberto of Savoy in 1923. In 1919-20, in front of the access road it was built a church dedicated to Santa Barbara patron air and naval forces to allow military and civilian residents to participate in religious worship.

An inscription, engraved on marble helix embedded on the wall of the first building, known as "house officers ", recalls the new heading seaplane to Ivo Monti, a lieutenant of the Royal Navy which took off from S. Nicola Imbuti, with his squadron, for various operations of war and that he died on a mission on the Croatian island of Lagosta, then under the control of the Austrians, June 2, 1918.

By Royal Decree of the 28 March 1923 it was founded the Royal Air Force that received over by Army and Navy all terrestrial aeronautical fields and seaplane then existing.

Subsequently, after a period of inactivity, the complex and the structures they were rearranged and reused starting from 1936 and during the second world war when they became seat of a section of sea rescue equipped with two seaplanes Cant Z.506 Airone.

Since the war until today the complex has undergone a constant and unstoppable degradation that the respect of its historical memory would suggest to arrest.

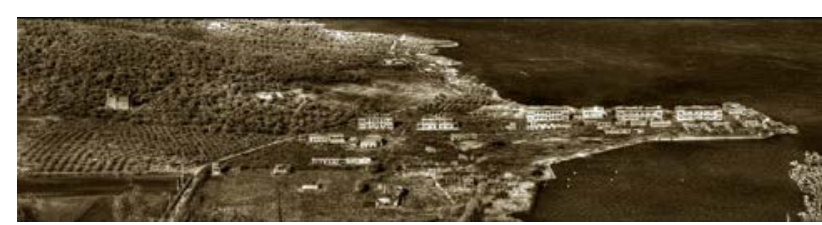

Figure 6. Aerial view of the complex

\subsection{Mapping and analysis of the state of the sites***}

As of today, there are no up-to-date graphic representations faithfully interpreting the architectural information of the site, the robustness of it, and the state of preservation of the ruins.

Moreover, the entire area surrounding the military complex is still missing a proper morphologic examination carefully tracking the blueprint, the borders, and the altitude development. By looking at the research conducted so far on the site, it is easy to find evidence of this. The latest geometric mapping of the ruins cannot indeed be considered neither exhaustive nor reliable both because it presents an insufficient level of detail and because it did not result from a mapping carried out on the actual historical site.

The data of the latest site analysis we have is summarised in two graphic illustrations.

The first is a mapping, carried out from the navy in 1951, and now kept in the navy historical archives, in the city of Brindisi. It was done as part of a preliminary study aimed at a militaryoriented conversion of the site which later did not happen. In such study, a dimensional mapping of the ruins is carried out, along with a very simplified ranking of the buildings by state of preservation. A general blueprint further distinguishes the different spaces of the buildings with the use of different colours, with each shade representing the state of decay of the spaces (Poor, mediocre, sufficient, good, to be demolished). One could argue that, considering the complete state of neglect the site has experienced since the 1950s, the latest geometric mapping could still be a very reliable source as the setting of the ruins has essentially remained unchanged. However, the state of deterioration of the materials caused by the amount of years passed, and the collapse of some of the structures show just how badly a new study is needed.

The secondi is a general overview of the state of the site carried out in 2007 as a part of a project aimed at increasing the tourist inflow of the area. The resulting data, obtained thanks to the private initiative of a group of citizens, were entrusted (and still are kept) in the city council offices of the city of Cagnano Varano (located in the district of Foggia, one of the six districts of Apulia). The mapping in question however only presents a summary of the dimensions of the spaces, and does not include any information concerning the state of preservation of the ruins, namely the state of decay of the materials and an account on the stability of the structure involved.

This geometric mapping is therefore not sufficiently detailed to be considered as a throughout analysis of the historical location for various reasons. Firstly, the results were developed only on a 1:100 scale or below and secondly, the discrepancies found between the actual state of the structures and the data of the mapping show that the analysis was not performed directly on site but it resulted from an interpretation of pre-existing reports, including the extremely misleading land register blueprints.

To fill the considerable gaps created by the old analysis and to put in place a conservation and valorisation plan for the former seaplane base, a sound inspection, and a study on the state of the decay of the materials and the structures are therefore needed. That is why, the first step of the research activity was to 
fill those above-mentioned gaps by carrying out a geometric mapping of the site ${ }^{1}$.

The newest geometric mapping of the site was done with the help of a new technology, as the more well-known traditional tools could not be used due to three main reasons: firstly, the great extension of the area; secondly, the advanced state of decay of the spaces, which makes mapping through traditional instruments, like laser scanners, quite burdensome; lastly, an overgrown flora that, by covering the majority of the surface of the site, makes difficult to operate a sound calibration concerning the dimensions of the spaces and the altitude range of the ground.

The new equipment called "UAV"2 was a concession by firm "E.V.E..S.r.l." ${ }^{3}$, our partner on this project, and allowed us, by using a Differential Global Positioning System ${ }^{4}$ (DGPS) technology, to obtain a sound mapping to the nearest 10 centimetres.

A first model was therefore built after the mapping of the more representative buildings of the site: the officers' barracks, the nearby administrative offices, the dormitories of the soldiers, and the infirmary flanking the lagoon. The drone-assisted acquisition of the images was carried out at the end of these two steps: firstly, different rectangular markers (either white or black) were positioned in some of the key points of the ruins that weren't covered by thick vegetation; secondly, a GPS stick was used to detect the position of each one of those markers. The output of the analysis was registered in a ".txt" file which provided the researchers with a chronological list of coordinates $\mathrm{X}, \mathrm{Y}, \mathrm{Q}$, according to the reference ellipsoid WGS84. These coordinates were subsequently interpreted with a Gauss-Boaga projection (zone 2) with the help of the coordinate maps belonging to the institution "IGM"

The DGPS system, differently from a more traditional GPS6, allowed us to obtain a high-precision mapping (to the nearest ten centimetres), thanks to the elimination of errors and disturbances of the signal transmission. One example of such errors, are, for example, atmosphere-influenced interferences, which cause a delay in the propagation of the GPS signals.

Once placed the markers at the relevant spots, and taken the right coordinates of each of those through a DGPS, it was possible to proceed with the drone-aided graphic analysis of the ground. Once the photo recon mission was concluded, both the DGPS-related coordinates (a total of 59 points were obtained) and the drone-acquired images where uploaded onto a specific software which could generate a "DEM"7 model. This model was composed of different polygons mesh (which also included texture details of the spaces) from which was then built a final

${ }^{1}$ The entire data-acquisition campaign was done as part of a workshop related to the class of "Architectural Restoration", a course which is part of the MSc of EngineeringArchitecture, at the Marche Polytechnic University. The project was done in collaboration with the city council of the city of Cagnano Varano.

${ }^{2}$ Unmanned aerial vehicle

${ }^{3}$ Spin-off firm of Marche Polytechnic University. The company develops high-tech multimedia products and services, mainly intended for use in fields such as architecture, fine arts, culture, and museum-related activities, along with various other professional or commercial applications.

${ }^{4}$ From here on "DGPS"

${ }^{5}$ Istituto Geografico Militare

${ }^{6}$ Global Positioning System

${ }^{7}$ Digital Elevation Model
"DSM"8 model and a high-resolution georeferenced orthophoto.

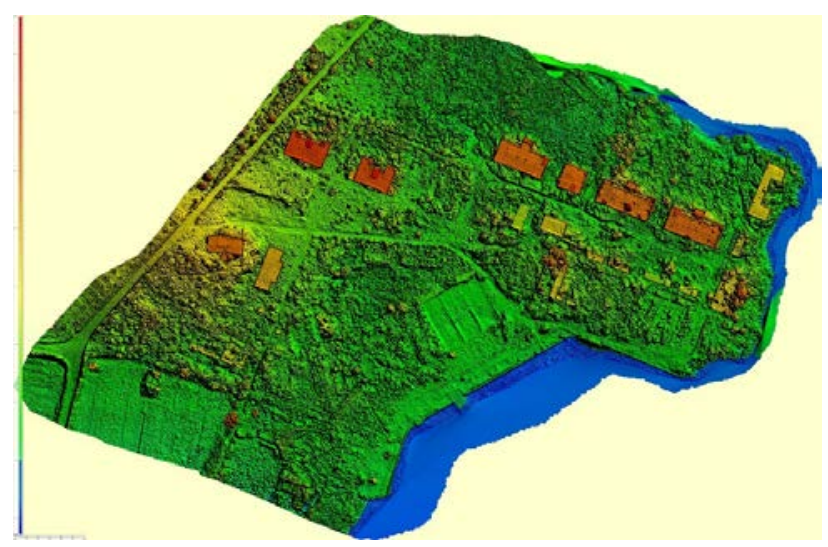

Figure 7. DSM model

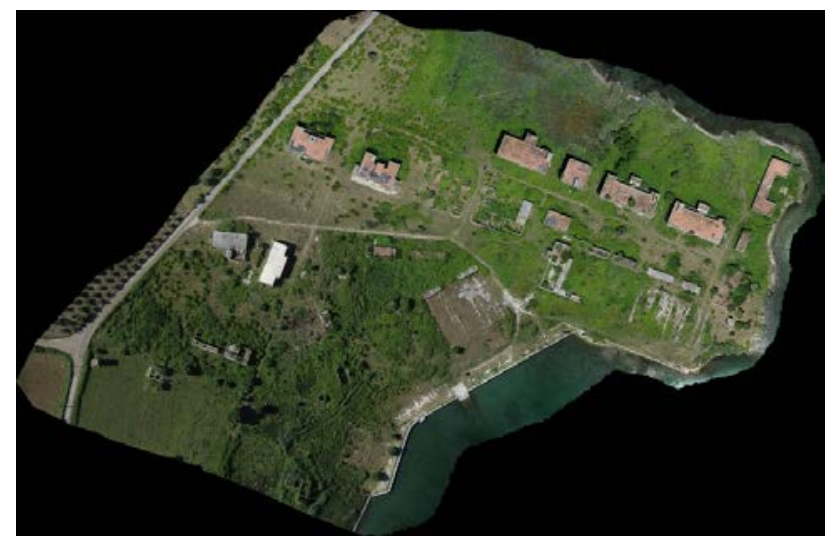

Figure 8. Orthophoto

Through the digital processing of the mapping carried out, a cloud of reference points was extracted. This cloud made possible to obtain an up-to-date plot of contour lines of the site. The latter, along with the different silhouettes related to the ruins, was graphically represented in a two-dimensional editable output, by using the most commonly-known drafting software applications. To this final graphic illustration was integrated the dataset relating to the seven buildings that we already mentioned above.

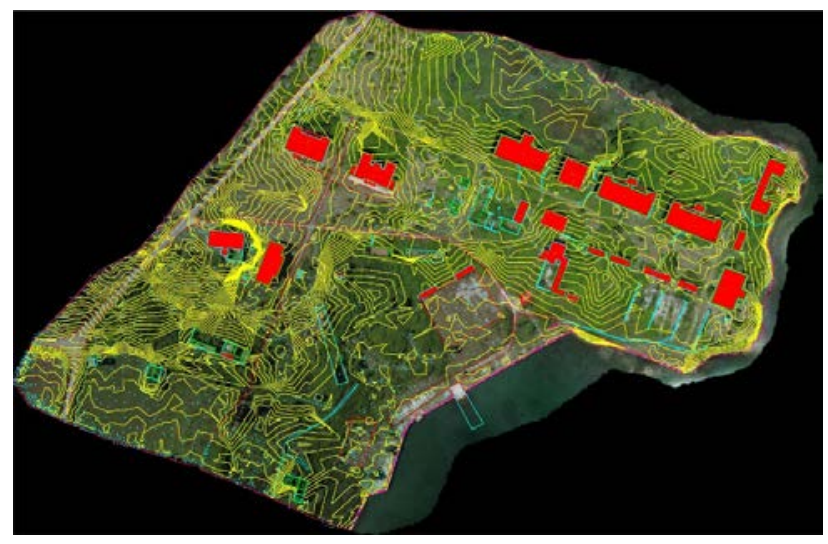

Figure 9. Contour map

${ }^{8}$ Digital Surface Model 
The images obtained through both the on-ground inspection and the drone-assisted examination, were assembled and geometrically rectified. Through this rectification, photomaps of the front of the different buildings were obtained, and by cross-checking the date coming from latter with the ones of the geometric mapping, it was possible to have a scale, twodimensional perspective planes.

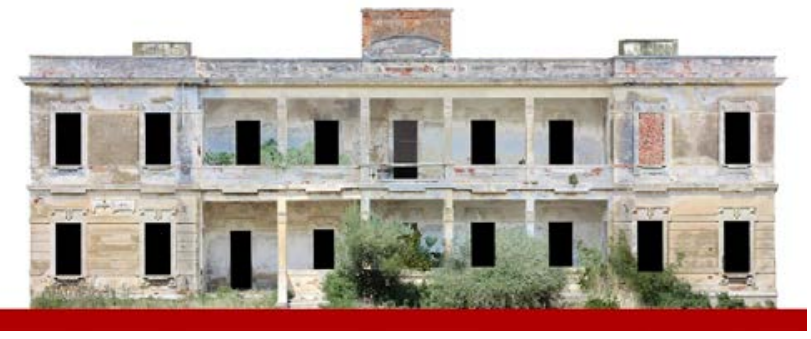

Figure 10. South facade of official barracks

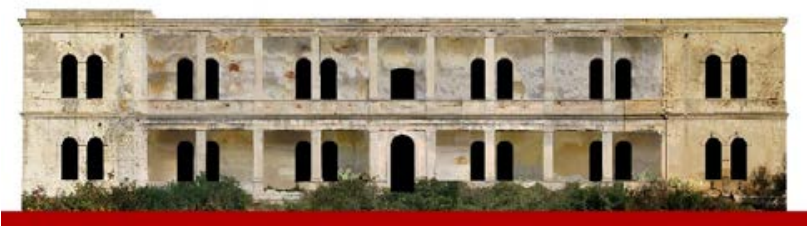

Figure 11. South facade of the dormitory for soldiers

As of now, the geometric mapping mentioned previously in this paper, represents the most up-to-date graphic illustration related to the former seaplane base site.

As stated beforehand, because of the dismantlement of the military base, the state of neglect, and the more general state of decay of the site, the only interest shown towards the ruins is an erroneous blueprint carried out for the land register.

\subsection{The current state of the research and the expected results.**}

As of now, the activities conducted on the historical complex have allowed us, through the latest geometric mapping, to acquire an up-to-date graphic illustration of the site and the surrounding area, which were not able prior to our study ${ }^{9}$. This study is going to lay the foundation for any further study carried on in the future. The next step will consist in detecting the different materials employed for the construction of the former military complex, as well as the different construction techniques applied. The latter part is going to be particularly interesting, seeing the general technological shift concerning any building practice at the beginning of the $20^{\text {th }}$ century.

The pace at which the complex developed, required an update on the construction techniques adopted up to that moment, as a faster approach was being required, due to the escalation of WWI.

Therefore, usual techniques and traditional materials, widely used on the older buildings, were replaced by modern products and technologies, more functional to the faster approach required, and used both in the main body of the buildings and in their finishes.

${ }^{9}$ The mapping available to us before the 2015 research we very approximate and quite incomplete
The different construction solutions applied to this complex represent therefore an assemblage of mainly experimental technologies and materials, in an architectural context very peculiar from both a ceremonial and an historical point of view.

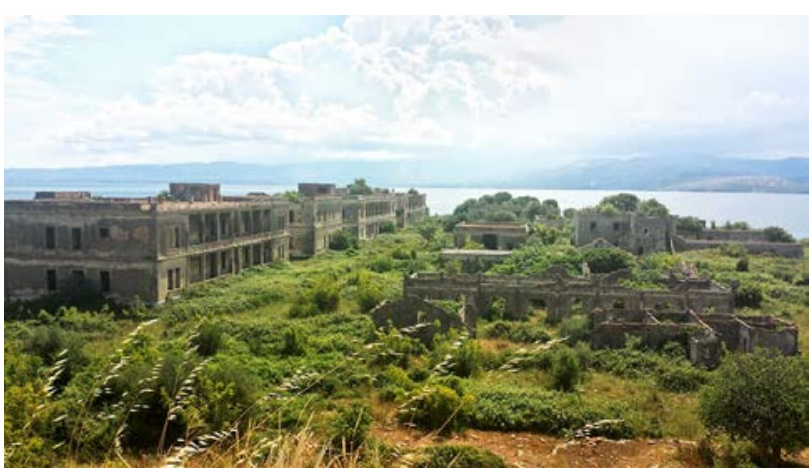

Figure 12. View of the complex

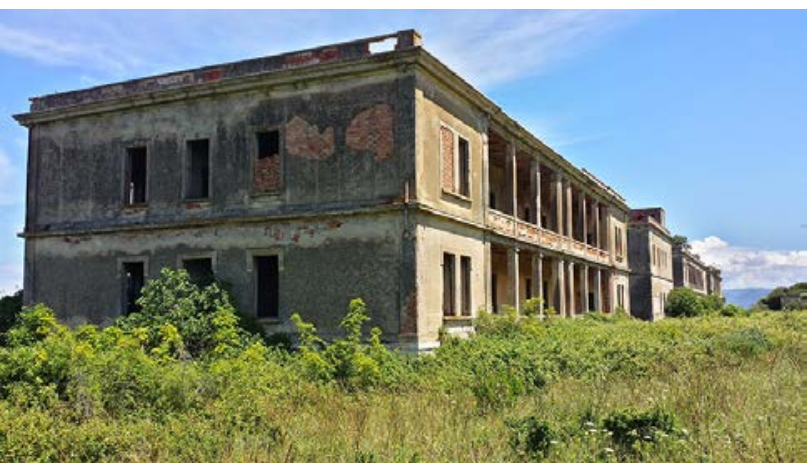

Figure 13. The fronts of the accommodation buildings along the main street

A first inspection revealed the presence of four typologies of walls, resulting from different techniques like the use of stone in square blocks (mainly in older facilities) or the creation, in the newer buildings, of load-bearing walls with hollow bricks (in different shapes and dimensions).

The floors have been arranged in different solutions, ranging from metallic-based attics with hollow bricks shaped according to their position, to poorly reinforced cinder-block-based ones, to ones with lightly reinforced casted concrete.

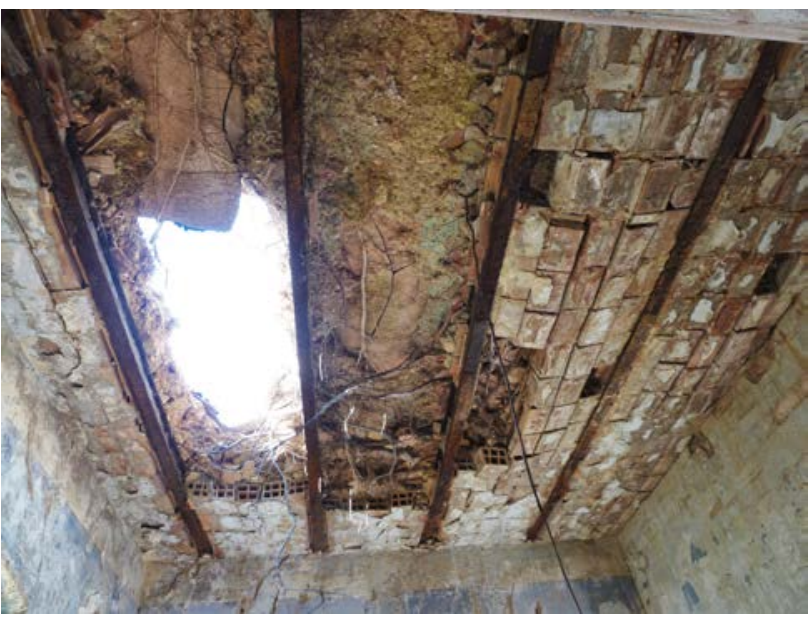

Figure 14. The types of floor 


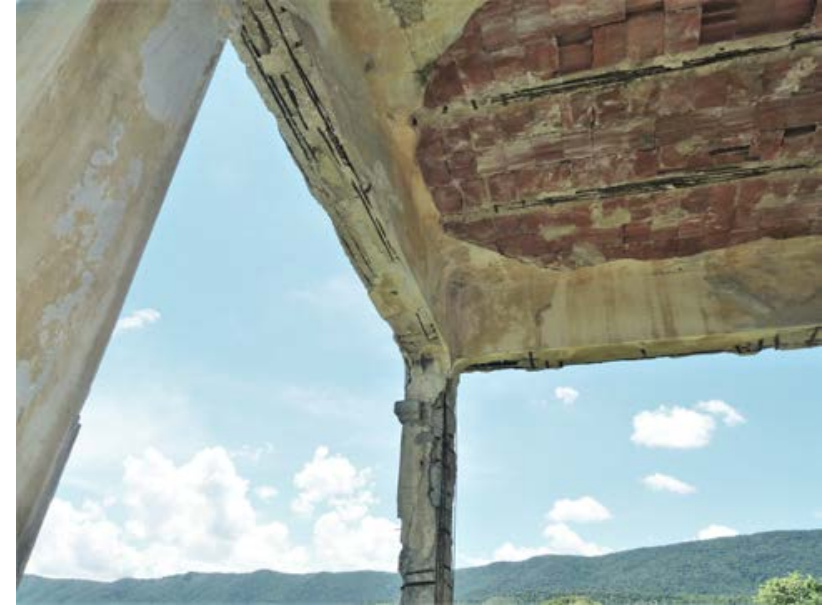

Figure 15. The types of floor and elements in reinforced concrete

The complex presents a unique variety of material uses, starting from the construction metals used, the reinforced concrete posts (which seems to be made of an allow of carbon, close to ductile iron), and the hollow bricks presenting unusual sizes and shapes, probably linked to building techniques developed around the 1900s, which were later abandoned.

Even the flooring system present more modern materials, like the concrete-based coatings instead of more common limebased ones, or the enormous variety of decorated polychrome concrete tiles found on internal floors of the facilities, linked to the early 1900s.

Because of this peculiar mix of uncommon construction oddities, not in line with the methods of the time, the construction materials will have to undergo chemical, physical, mineralogical, and petrographical analysis.

The source of such materials is still uncertain and it will be the core interest of future studies, defining future conservationoriented strategies. Future research will therefore compile a list of the different elements and the construction materials found, and develop detailed folders for each, which will be later organised in a "Geographic Information System".

The actions taken to tackle the conservation and the restoration of the site will prepare for the recover and reuse of the complex. Moreover, considering the state of decay of the buildings, the site will experience a structural reinforcement and readjustment coherent with the new intended use of the complex.

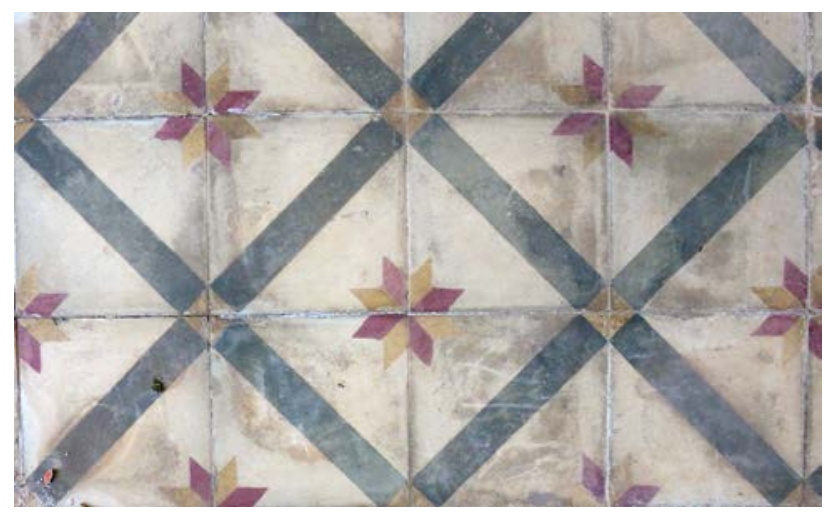

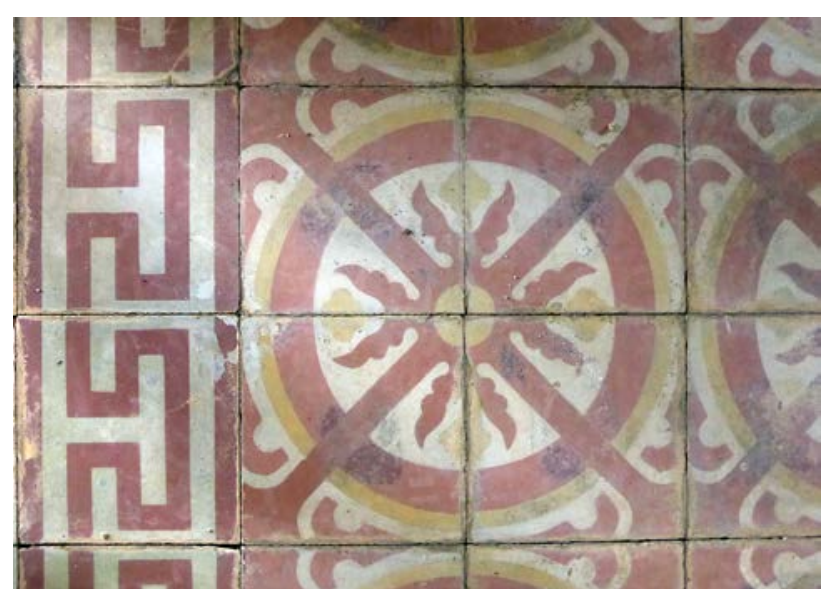

Figure 17. Floor coatings

\subsection{Conclusions**}

The study of the complex, which represents a clear example of contemporary military archaeology, is part of a research study sector whose main interest is past military architectures and who, in the last 10 years, has been shifting the focus on defence-oriented military constructions built during the 20th century. An example of such involvement are the research studies aimed at the conservation and the valorisation of WWI and WWII military constructions of the northern Adriatic coast (part of the 2015 CAMAA project), which interested both Italian and Slovenian territories

Just as importance is also the study, carried out in the region of Sardinia, of the defensive system of the island (Fiorin, Pintus, 2015). These studies have been carried out for a long time now and have been increasingly including the large abandoned military complexes.

Very relevant to the subject is also the attention the authorities have been shifting on the WWI architectural heritage, especially with the law n.78 of 7th May 2001 stating that "the State and the regions promote the recognition, cataloguing, maintenance, restoration, management, and valorisation of the remnants of both parts of the conflict".

The conservation and the restoration of such military architectures is therefore important to present evidence of both the events of the two world wars and the military strategies used then but now outdated and characterised by a high level of technological and typological specialisation".

An increasingly relevant topic is therefore the restoration, the recovery, and the reconversion, compatible to their material composition, of such $20^{\text {th }}$ century architecture, often presenting experimental materials. Such readjustment plans should also be sustainable and efficient, both from the management and the financial point of view.

Conclusively, it must be mentioned that, like in the case of the "Ivo Monti" seaplane base, the areas in which such complexes are located, have a clear environmental relevance, and need attention in terms of the intervention and valorisation strategies to be applied, action plans which should naturally receive national attention.

Figure 16. Floor coatings 


\section{REFERENCES}

Aa.Vv., 1927, L’Esercito italiano nella Grande Guerra (19151918), vol. I, Roma, Italy.

Crisetti Grimaldi L., 1995, San Nicola Imbuti: ricerca storica, Vico del Gargano, Italy.

Crisetti Grimaldi,L., 1999, Cagnano Varano, centro storico, economia, salute, costumi, società,Manfredonia, Italy.

Ferrantem. A.,2002, Memorie di guerra dall'idroscalo (lago Varano 1915-1918), Foggia, Italy.

Fiorino D.R., Pintus M., 2015, Verso un atlante dei sistemi difensivi della Sardegna, Napoli, Italy.

Progetto Camaa, 2015, Pubblicazione finale, Lubiana, Slovenia, http://www2.regione.veneto.it/cultura/cms/allegati/CAMAA/CA MAA_NET_2105.pdf, (10 march, 2017)

Archive sources

Ufficio Storico Marina Militare, Roma:

- 1906, b. 193. f. 1, Lago di Varano:voto al governo per la trasformazione in porto mercantile militare, 1906.

- 1916, b. 656, .. 2, Squadriglia idrovolanti di Varano, 1916.

- 1917, b. 905, f. 8, Lavori al '917, Roma, 1917.

- 1922, b. 1656, Rapporto di efficienza stazione idrovolanti di Varano, 1922.

Archivio Civile di Stato, Roma:

- P.C.M. 1917, b. 535, '.10/1, Richiesta di vettura salone per S.E. il VICE Ammiraglio Paolo Thaon di Revel , Roma 12-021917.

- 1917, b. 701, Azioni aeree nel Raid adriatico, azione degli aerei nel Varano contro altri nemici. Roma, 1917. 